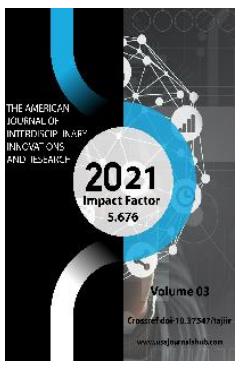

Journal Website: https://theamericanjou rnals.com/index.php/ta jiir

Copyright: Original content from this work may be used under the terms of the creative commons attributes 4.0 licence.

\section{Prospects For Application Of Non-Metal Composite Valves As Working Without Stress In Compressed Elements}

\author{
Shokhrukh Muratovich Davlyatov \\ PhD, Ferghana Polytechnic Institute, Fergana, Uzbekistan \\ Webmail: sh.davlyatov@ferpi.uz \\ Bakhromjon Ikromjon Ugli Kimsanov \\ Assistant, Ferghana Polytechnic Institute, Fergana, Uzbekistan \\ Webmail: b.kimsanov@ferpi.uz
}

\title{
ABSTRACT
}

An analysis is given of the possibility of using glass-composite non-metallic reinforcement in compressed concrete elements. The results of comparison of studies of strength and deformability with high-strength composite and steel (class A800) working reinforcement in our country and abroad are presented. Proposals are given for further research of composite reinforcement as longitudinal in compressed elements.

\section{KEYWORDS}

Composite reinforcement, compressive strength, elastic modulus, yield strength, testing.

\section{INTRODUCTION}

Reinforced concrete compressed elements are the main load-bearing vertical structures of buildings and structures for various purposes, taking the load from floors and coverings, transferring it to the foundation and further to the base soils. Therefore, along with reliability, they must have high economic performance and corrosion resistance, which largely depends on the materials used and calculation methods. Prospects for the development of reinforced concrete are inextricably linked with the use of both new materials and their combination with already proven traditional materials [1]. Along with this, there is an optimization of the already proven structural solutions of reinforced concrete structures [2, 3]. 
Reinforcement in reinforced concrete structures is used primarily to absorb tensile forces and reinforce concrete in compressed zones of structures. Therefore, in the normative document on the design of reinforced concrete structures [4], the normative and design characteristics of the reinforcement in tension and compression are assigned. The tensile work of the reinforcement is determined by its physical and mechanical characteristics (yield point and elastic modulus) obtained during testing.

\section{THE MAIN FINDINGS AND RESULTS}

The design resistance of the reinforcement to compression is determined to a greater extent by the ultimate compressibility of concrete $\varepsilon_{\text {bu }}$ $=2 \cdot 10^{-3}$ The ultimate compressibility of concrete depends on the strength of the concrete, its class, composition, and the duration of the load application. With an increase in the class of concrete, the ultimate deformations decrease, however, with an increase in the duration of the load application, they increase.

Since, due to adhesion, the reinforcement is deformed together with the concrete $\varepsilon S c=$ cbu, then the limiting stresses in it are determined by the formula (Hooke's law)

$$
\begin{gathered}
\sigma_{s c h, u}=\varepsilon_{s c} \cdot E_{s}=2 \cdot 10^{-3} \cdot 2 \cdot 10^{5} \\
=400 \mathrm{MPa}
\end{gathered}
$$

where Es is the modulus of elasticity of steel. Consequently, the design resistance of steel reinforcement will be equal to $\mathrm{Rsc}=400 \mathrm{MPa}$, which is accepted in modern design standards [4].

If the applied load acts for a long time, then due to the creep of concrete, the ultimate compressibility increases, therefore, the design compressive strength of the reinforcement can be increased to $500 \mathrm{MPa}$, although the actual compressive stresses can reach large values. In this case, of course, the design resistance cannot exceed the design yield strength of the steel, i.e. $R_{s c}<R_{s}$. From the above, we can conclude that steel reinforcement of both $\mathrm{A} 500$ and $\mathrm{A} 600$ classes is better suited as compressed reinforcement under prolonged exposure. Compression resistance of reinforcement of higher classes (A800, A1000) turns out to be underutilized. It can be noted that the indicated calculated values of the limiting deformability of concrete cbu are taken in the norms to be the same for concrete of all classes. However, in fact, with a decrease in the class of concrete, its deformability increases, along with this, ebu will also increase and, therefore, the ultimate stress for reinforcement will increase.

It is known that if a transverse reinforcement is installed in a compressed element, which is capable of effectively restraining transverse deformations, then this can significantly increase its bearing capacity. Experiments have shown that concrete has an increased resistance to compression within the core, enclosed within the transverse reinforcement, by analogy with pipe concrete. When compressed, flexible reinforcing bars tend to lose stability (bulge) long before the ultimate strength is exhausted and tear off the protective layer of concrete, which can cause premature destruction of structures. To 
prevent this dangerous phenomenon, it is necessary to install transverse reinforcement (clamps). The transverse reinforcement, like a cage, restrains the transverse deformations of concrete arising during longitudinal compression, and thus causes an increased resistance of concrete to longitudinal compression, incl. and after the appearance of the first longitudinal cracks in it. The concrete within the core resists external influences even after peeling of the outer concrete layer and until the stress in the transverse reinforcement reaches the yield point. Longitudinal deformations of elements reinforced with indirect reinforcement are very large and the greater, the stronger the transverse reinforcement.

The works of some researchers have shown [57] that in the presence of a certain amount of transverse reinforcement, it is possible to limit transverse deformations in concrete, and, consequently, an increase in longitudinal deformations according to Poisson's law, which, accordingly, will lead to an increase in ultimate stresses in compressed reinforcement. So, it was proved that when using a sufficient amount of transverse reinforcement as a compressed one, reinforcement of classes AT800 (AT-V) with stresses up to the yield point can be used. The studies obtained helped to introduce highstrength steel reinforcement of the AT800 class into real structures (columns produced at the Mospromzhelezobeton plant).
Composite rebar offers a number of advantages over traditional steel rebar. These are low weight, high strength, corrosion resistance, transparency to magnetic fields. The disadvantages of such reinforcement are low modulus of elasticity (4 times compared to steel bar reinforcement), fragility upon fracture (no yield strength) and susceptibility to a decrease in strength under high temperatures.

The use of non-metallic composite reinforcement (in particular, based on glass fibers) as compressed non-stress reinforcement instead of traditional steel reinforcement in reinforced concrete elements will increase the corrosion resistance of compressed elements operating in corrosive environments (tanks, silos, offshore structures, etc.). This will provide an economic effect by reducing the operating costs associated with the absence of the need for frequent repair, reinforcement or replacement of structures due to corrosion of the steel reinforcement. Glass composite reinforcement (due to its low cost compared to other types of non-metallic reinforcement, it accounts for the vast majority of the use of composite reinforcement) is comparable in cost to steel reinforcement and may well be used as a replacement for steel in reinforced concrete structures operating in corrosive environments. The table shows the main comparative characteristics of traditional steel and non-metallic composite reinforcement.

Comparative characteristics of steel and fiberglass reinforcement

\begin{tabular}{|c|c|c|c|c|c|c|}
\hline Indicator name & $\begin{array}{l}\text { A400 } \\
\text { (A-III) }\end{array}$ & A500 & A600 & A800 & A1000 & ASK \\
& (AT-IIIC) & (A-IV) & (A-V) & $(\mathrm{A}-\mathrm{VI})$ & \\
\hline
\end{tabular}


The American Journal of Interdisciplinary Innovations and Research (ISSN-2642-7478)

Published: September 30, 2021 | Pages: 16-23

Doi: https://doi.org/10.37547/tajiir/Volume03Issue09-05

\begin{tabular}{|c|c|c|c|c|c|c|}
\hline Yield strength, MPa & 400 & 500 & 600 & 800 & 1000 & - \\
\hline Ultimate tensile strength, MPa & 500 & 600 & 740 & 1000 & 1200 & 1200 \\
\hline $\begin{array}{c}\text { Tensile elongation,\% } \\
\text { Elastic modulus in tension/ } \\
\text { compression, GPa }\end{array}$ & 16 & 14 & 12 & 8 & 7 & 2,5 \\
\cline { 2 - 7 } & 200 & 200 & 200 & 200 & 200 & 50 \\
\hline $\begin{array}{c}\text { Compressive strength } \\
\text { Design Compression Resistance }\end{array}$ & 400 & 500 & 600 & 800 & 1000 & 30 * $^{*}$ \\
\hline & $435(400)$ & $\begin{array}{c}470 \\
(400)\end{array}$ & 500 & 500 & - \\
\hline
\end{tabular}

$\therefore 1 \quad$ Note. The Rsc value in brackets is used only for short-term loading.

* - the method for determining and the requirements for the value of the modulus of elasticity in compression are not defined.

However, there are practically no experimental data on the strength and deformability of compressed elements reinforced with composite non-metallic reinforcement. Therefore, the design standards of Western countries [8-11] either do not contain methods for calculating compressed members with nonmetallic reinforcement, or allow its use, but with zero design compressive strength [12]. In our country, design standards for structures with composite reinforcement have not yet been developed.

Also, one of the problems of using composite reinforcement is the uncertainty in obtaining the compression characteristics of composite reinforcement. Abroad, there are no standard methods for testing composite reinforcement for compression, mainly due to the many different types of fracture patterns [8]. The nature of the destruction of samples can be expressed both in the loss of stability of the entire sample and in individual fibers. For flat sheet composites, many axial compression test procedures are some kind of variation ofCelanese compression tests, as in ASTM
D3410 (2008) or ASTM D695-10 [13] for rigid plastics.

This method assumes a thin, straight-sided specimen, which is very similar to the specimen in central axial tension, except for the distance between the grips of the testing machine, which is much smaller. Compression testing of composite reinforcement bars is usually hampered by the appearance of fiber buckling due to the anisotropy and inhomogeneity of the composite material and lead to inaccurate measurement results. In view of this, standard test methods have not yet been established abroad. Different researchers for composite rods suggest different values of reduction in compressive strength - on average, from 30 to $50 \%$ of its tensile strength $[14,15]$.

In the Russian Federation, compression testing of composite reinforcement bars is regulated by GOST 31938-2012, which was put into effect since 2014 [16]. According to the methodology described in Appendix B [17], the test specimen consists of a piece of a rod, at the ends of which test sleeves are installed on 
the adhesive layer (Fig.). The total length of the specimen is determined by the design of the bushings. The length of the working section of the rod between the bushings should be $6 \mathrm{~d}$. The device for testing specimens for compression consists of a guide sleeve, which ensures the possibility of applying a load strictly along the axis of the rod, and two test sleeves installed at the ends and ensuring the destruction of the specimen in the working area.

Nevertheless, the methodology of GOST 319382012 [16] is based on the method of GOST 465182 [17], which was originally intended for structural plastics for gasket and sealing purposes, and not directionally fiberreinforced composite reinforcement rods, obviously differing in both structure and composition. and working conditions. The spread of compressive strength in $[14,15]$ and the difference in the nature of fracture depending on the test method indicates the difference and underestimation of the conditions for the real operation of composite reinforcement rods in concrete.

It should be noted that the method described in [16] does not imply the measurement of the modulus of elasticity in compression. Meanwhile, composite reinforcement is anisotropic and, therefore, multi-modulus material, i.e. the modulus of elasticity in compression and tension differ, as noted in [14, $15]$.

So, the modulus of elasticity of the composite reinforcement in compression is about $30 \mathrm{GPa}$, and the compressive strength is about $0.3 \ldots$ 0.35 of the tensile strength. In addition, GOST establishes the requirement for composite reinforcement for compression (Table 4 [16]) not less than $300 \mathrm{MPa}$. The requirements for the modulus of elasticity in compression are not mentioned in this standard, and as noted above, this characteristic is extremely important for assessing the calculated value of the compressive strength of composite reinforcement, especially in light of the upcoming set of rules for the design of structures with composite reinforcement ... Most likely, this document will not contain methods for calculating compressed members with composite reinforcement due to the aforementioned lack of test data for such structures.

In this regard, the provision of GOST [16], which imposes requirements for compressive strength and does not contain any requirements for the modulus of elasticity in the absence of calculation methods, does not seem entirely logical. 

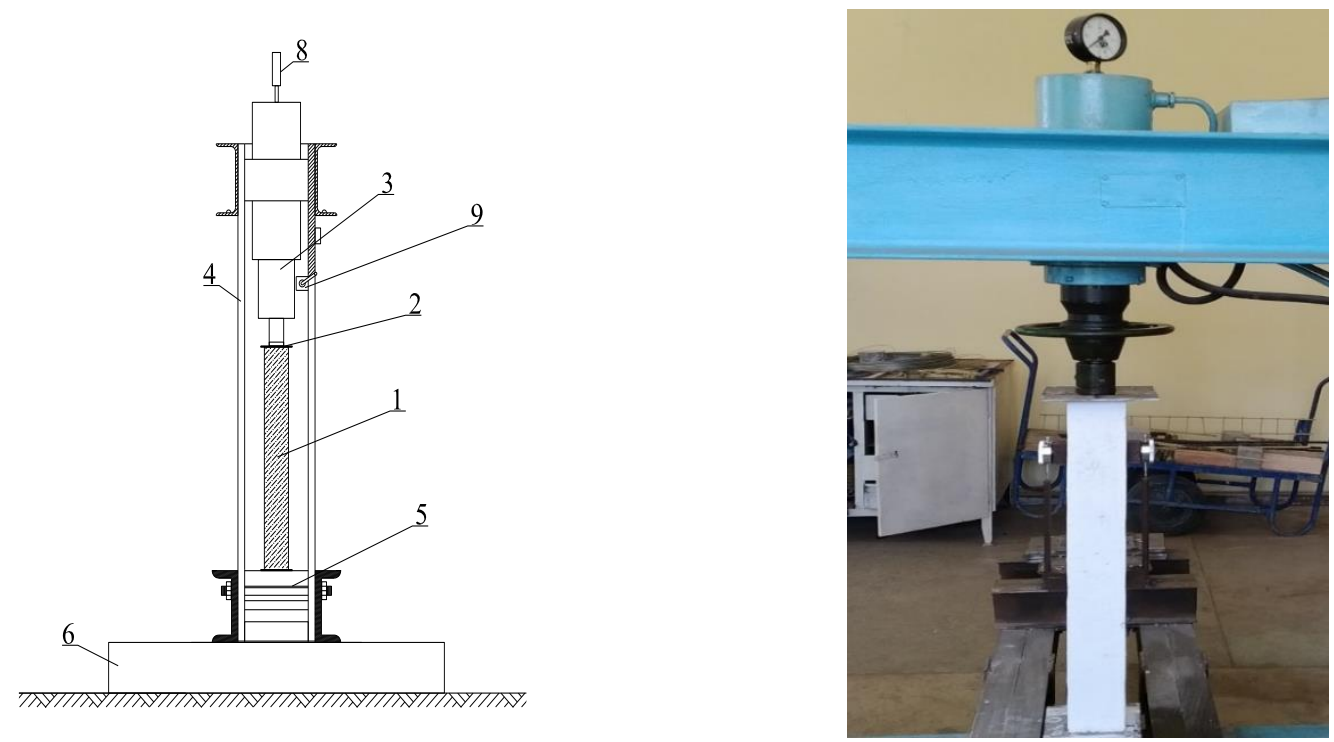

1 test sample, 2 load distribution traverses, 3 hydraulic dampers, 4 columns, 5 support columns, 6 base plates, 7 bases, 8 hydraulic jack manometers,

Type of compression tests of a fiberglass reinforcement bar in accordance with GOST 31938 2012: a - sketch in accordance with GOST 31938-2012; b - full-scale test sample

Thus, using Hooke's law (1), it is possible to obtain that the ultimate stresses in composite reinforcement at an elastic modulus of $30 \mathrm{GPa}$ will reach only about 50 ... $60 \mathrm{MPa}$, which can be comparable with the compressive stresses of concrete. At such stresses, taking into account the value of the percentage of reinforcement in compressed structures (usually no more than $2 \ldots 3 \%$ ), the share of the participation of composite reinforcement in the bearing capacity of the column will be very small, comparable to the calculation error, which greatly limits the prospects for its use in compressed elements. ...

However, as noted in foreign standards, and as shown in [18-19], the compressive strength of composite reinforcement should not be neglected.

Tests of columns reinforced with non-metallic composite reinforcement were carried out abroad. It was shown in [19] that the strength of columns with composite fiberglass reinforcement with a sufficient transverse step of reinforcement is only $7 \%$ lower than that of columns with steel reinforcement of a similar design, and the strength of columns with carbon fiber reinforcement is $5 \%$ lower than that of columns with steel reinforcement.

Studies carried out in our country by the author of this article showed [18] that with a sufficient amount of transverse reinforcement, with a step half the recommended rate, composite reinforcement gives an increase in strength up to 1.8 times compared to a pure concrete sample. At the same time, other studies show [20] that when clamps are installed with a pitch close to the upper limit of the norm, there is practically no increase in bearing capacity compared to pure concrete columns without reinforcement.

From the above, it can be concluded that compressed members with composite reinforcement should be designed using other methods than compressed members with steel reinforcement. Requires more frequent, in 
comparison with steel reinforcement, transverse reinforcement. At the moment, there are no universal calculation methods, despite a certain layer of accumulated research. For glass-composite reinforcement, the question of the optimal percentage of reinforcement with an accelerated setting of transverse reinforcement has not been studied.

\section{CONCLUSIONS}

1. The use of non-metallic fiberglass reinforcement is promising from an economic point of view in order to reduce the operating costs of buildings and structures operating in aggressive environments.

2. The studies carried out show that nonmetallic glass-composite reinforcement, with a reasonable setting of transverse reinforcement, can be used in compressed elements with a bearing capacity of only $5 \%$ less than similar samples with steel reinforcement.

3. Placing a sufficient amount of transverse reinforcement in compressed concrete elements increases the strength of columns with composite reinforcement up to 1.8 times compared to concrete specimens without reinforcement. 4. To substantiate the use of composite nonmetallic reinforcement in compressed elements and to introduce methods for calculating such elements into the design standards, it is necessary to carry out fullscale studies to study the effect on the strength and deformability of samples of such parameters as the shape of the crosssection of the samples, the pitch and diameter of the transverse reinforcement, the percentage of longitudinal reinforcement, eccentric and cyclic loads.

\section{REFERENCES}

1. Adilhodzhaev A. et al. The study of the interaction of adhesive with the substrate surface in a new composite material based on modified gypsum and treated rice straw //European Journal of Molecular \& Clinical Medicine. - 2020. - T. 7. - №. 2. - C. 683-689.

2. Akhrarovich A. K., Muradovich D. S. Calculation of cylindrical shells of tower type, reinforced along the generatrix by circular panels //European science review. -2016 . - №. 3-4.

3. Muratovich D. S. Study of functioning of reservoirs in the form of cylindrical shells //European science review. - 2016. - №. 910.

4. Davlyatov M.A., Abdurakhmanov U.A.U., Matisaeva M.A. Study of the influence of locally produced fiberglass on the strength characteristics of gypsum binder /l Problems of modern science and education. - 2018. - No. 11 (131).

5. Akhrarovich A. X., Mamajonovich M. Y., Abdugofurovich U. S. Development of Deformations In The Reinforcement of Beams With Composite Reinforcement //The American Journal of Applied sciences. - 2021. - T. 3. - №. 5. - C. 196-202.

6. Mahkamov Y. M. Study Of The Effect Of Heating On The Strength And Deformation Properties Of Concrete //The American Journal of Engineering and Technology. - 2020. - T. 2. - №. 11. - C. 6774.

7. Mahkamov Y. M., Mirzababaeva S. M. Strength of bending reinforced concrete elements under action of transverse forces under influence of high temperatures //ACADEMICIA: An International Multidisciplinary Research Journal. - 2020. - T. 10. - №. 5. - C. 618-624.

8. Mahkamov Y. M. Design Model Of Bending Reinforced Concrete Elements Under Action Of Transverse Forces Under Conditions of Increased And High 
Temperatures //The American Journal of Engineering and Technology. - 2020. - T. 2. - №. 10. - C. 17-24.

9. Makhkamov YM, Mirzababayeva SM Bending of bended reinforced concrete elements under the action of transversal forces and technological temperatures // Problems of modern science and education. - 2019. - No. 12-2 (145).

10. Makhkamov YM, Mirzababayeva SM Temperature deflections of reinforced concrete beams under the influence of technological temperatures // Problems of modern science and education. - 2019. No. 11-1 (144).

11. Akhrarovich A. X., Mamajonovich M. Y., Abdugofurovich U. S. Development of Deformations In The Reinforcement Of Beams With Composite Reinforcement //The American Journal of Applied sciences. - 2021. - T. 3. - №. 5. - C. 196-202.

12. Asrorovna A. Z. Effects Of A Dry Hot Climate And Salt Aggression On The Permeability Of Concrete //The American Journal of Engineering and Technology. 2021. - T. 3. - №. 06. - C. 6-10.

13. Y.M. Mahkamov - The American Journal of Engineering and Technology, 2020 Design Model Of Bending Reinforced Concrete Elements Under Action Of Transverse Forces Under Conditions Of Increased And High Temperatures.

14. Abobakirova Z. A. Regulation Of The Resistance of Cement Concrete With Polymer Additive And Activated Liquid Medium //The American Journal of Applied sciences. - 2021. - T. 3. - №. 04. - C. 172177.

15. Goncharova N. I., Abobakirova Z. A., Kimsanov Z. Technological Features of Magnetic Activation of Cement Paste" Advanced Research in Science //Engineering and Technology. - 2019. - T. 6. - №.

16. Muratovich D. S., Shavkatovich N. K. Influence Of Changes In Microclimate Parameters On Human Well-Being And
Operational Characteristics Of Building Structures //The American Journal of Engineering and Technology. - 2020. - T. 2. - №. 11. - C. 113-117

17. Davlyatov S. M., Makhsudov B. A. Technologies for producing high-strength gypsum from gypsum-containing wastes of sulfur production-flotation tailings //ACADEMICIA: An International Multidisciplinary Research Journal. - 2020. - T. 10. - №. 10. - C. 724-728.

18. Goncharova N. I., Abobakirova Z. A. RECEPTION MIXED KNITTING WITH MICROADDITIVE AND GELPOLIMER THE ADDITIVE //Scientific-technical journal. 2021. - T. 4. - №. 2. - C. 87-91

19. Goncharova N. I., Abobakirova Z. A., Mukhamedzanov A. R. Capillary permeability of concrete in salt media in dry hot climate /IAIP Conference Proceedings. - AIP Publishing LLC, 2020. T. 2281. - №. 1. - C. 020028.

20. Mirzazhonovich G. G., Ogly AUA, Ogly H. A. $M$. Influence of hydrophobizing additives on the thermophysical properties and long life of expanded clay concrete in an aggressive environment / / American Journal of Engineering and Technology. 2020. - Vol. 2. - no. 11. - pp. 101-107.

21. Akhrarovich A. X., Mamajonovich M. Y., Abdugofurovich U. S. Development Of Deformations In The Reinforcement of Beams With Composite Reinforcement //The American Journal of Applied sciences. - 2021. - T. 3. - №. 5. - C. 196-202. 